\title{
Facing the Environment: Small RNAs and the Regulation of Gene Expression Under Abiotic Stress in Plants
}

\author{
Inês Trindade ${ }^{1}$, Dulce Santos ${ }^{2}$, Tamas Dalmay ${ }^{3}$ and Pedro Fevereiro ${ }^{1}$ \\ ${ }^{1}$ Laboratório de Biotecnologia de Células Vegetais \\ Instituto de Tecnologia Química e Biológica \\ Universidade Nova de Lisboa \\ ${ }^{2}$ Centro de Veterinária e Zootecnia, Instituto de Investigação Científica e Tropical \\ Universidade Técnica de Lisboa \\ ${ }^{3}$ School of Biological Sciences \\ University of East Anglia \\ 1,2Portugal \\ 3 United Kingdom
}

\section{Introduction}

Plant growth and development is highly dependent on a variety of environmental conditions such as temperature, light, water availability and soil conditions that strongly affect productivity worldwide. Over the past years, several reports have raised awareness for the fact that extreme weather conditions are predicted to become more frequent in a near future, which is likely to have a strong impact in crop production. For instance, it is estimated that by 2030, global water demand solely for agriculture may have increased by more than $30 \%$ as a consequence of foreseen climate changes (Foresight, 2011). Therefore, there is an urgency to understand how plants behave when facing adverse conditions, in order to reduce productivity losses in sub-optimal environments.

Plants have developed different strategies to cope with abiotic stress conditions. Upon environmental stimuli, changes in metabolism, signal transduction pathways and gene expression can be detected (Shinozaki \& Yamaguchi-Shinozaki, 2007). Post-transcriptional regulatory mechanisms, as well as epigenetic and post-translational modifications, like ubiquitination and sumoylation, seem to play an important role in the regulation of gene expression in stress conditions (reviewed in Hirayama \& Shinozaki, 2010).

In this chapter we will provide evidences of the involvement of small RNAs (sRNAs) in the regulation of gene expression as response to abiotic stress. The role of microRNAs (miRNAs) and other sRNAs under water deficit, high salinity, cold and oxidative stress, among others, as well as their relation to hormone signalling in plants, will be reviewed. Moreover, we will show that key enzymes involved in sRNA synthesis pathways also seem to be regulated upon environmental stimuli, affecting the expression of most sRNAs and consequently of several genes. 


\section{Plant small RNAs}

Evidence for the existence of RNA-mediated silencing mechanisms in plants first appeared in the late 1990's, when short antisense RNA molecules were isolated from tomato plants where post-transcriptional gene silencing (PTGS) had been detected (Hamilton \& Baulcombe, 1999). Since then, the knowledge on sRNAs has broadened and these molecules have been identified as important players in a wide variety of processes in plants. Back in 2002, when the first set of plant microRNAs (miRNAs) was cloned (Reinhart et al., 2002), there were 218 entries in the public miRNA database (miRBase; Griffiths-Jones, 2004) whereas nowadays more than 15000 entries can be found.

The biosynthesis of sRNAs is triggered by the presence of double-stranded RNA (dsRNA) molecules that are processed into small RNA duplexes by RNase III Dicer-like (DCL) proteins (reviewed by Bartel, 2004). S-adenosyl methionine-dependent methyltransferase Hua Enhancer 1 (HEN1) methylates these molecules at the $3^{\prime}$ end, in a sequenceindependent manner, protecting them from uridylation and degradation (Park et al., 2002; $\mathrm{Li}$ et al., 2005; Yu et al., 2005). There are 4 loci in arabidopsis and rice (Oryza sativa) that encode for DCL proteins (Liu et al., 2005). Although some functional redundancy has been observed, each DCL seems to have a specific role in sRNA biosynthesis pathways (Bouche et al., 2006; Henderson et al., 2006).

Following methylation, sRNAs are incorporated into ARGONAUTE (AGO) proteins, in order to act upon targets in a sequence-specific manner (Llave et al., 2002b; Rhoades et al., 2002; Vazquez et al., 2004). Plants have multiple loci encoding for AGO proteins: 10 are known in arabidopsis and at least 18 in rice (Mallory \& Vaucheret, 2010). AGO4, AGO6 and AGO9 are usually involved in silencing at the transcriptional level, by association with 24-nt sRNAs, whereas AGO1 and AGO7 participate in post-transcriptional gene silencing and are usually loaded with 21 and 22-nt sRNAs (reviewed in Mallory \& Vaucheret, 2010). Recently, a role for AGO2 in responses to virus infection has also been described (Harvey et al., 2011). With few exceptions, the main characteristics that influence the loading of AGO proteins in plants are both the size of the sRNAs and the nature of the nucleotide at the 5' end (Mi et al., 2008; Mallory \& Vaucheret, 2010).

Depending mainly on their origin, sRNAs can be roughly divided into two distinct classes: miRNAs (Fig.1A) and small interfering RNAs (siRNAs, Fig.1B and 1C) (Hamilton et al., 2002; Rajagopalan et al., 2006).

\subsection{MicroRNAs}

miRNAs are usually transcribed from intergenic regions (Llave et al., 2002a; Reinhart et al., 2002) by Polymerase II (Pol II) into 5' capped and 3' polyadenylated primary transcripts, in a way similar to protein-coding genes (Xie et al., 2005). These precursors (named pri-miRNAs) have regions of self-complementarity and can therefore fold back into stem-loop structures (Park et al., 2002; Meyers et al., 2008), yielding the dsRNA region, needed to trigger RNA silencing mechanisms. The hairpin precursors, called pre-miRNAs, are released from the pri-miRNAs by DCL1 in the nucleus. DCL1 then processes the pre-miRNAs into smaller duplexes bearing the mature miRNA and the complementary strand (miRNA*) (Reinhart et al., 2002; Henderson et al., 2006). In plants, both HYPONASTIC LEAVES1 (HYL1) and SERRATE (SE) proteins seem to interact with DCL1 and are also required for this process (Han et al., 2004; Lobbes et al., 2006). 
At this point in the biosynthesis pathway, miRNAs can either stay in the nucleus or be transported to the cytoplasm, a process that seems to be dependent on HASTY protein, an exportin homolog (Bartel, 2004; Park et al., 2005). Either way, mature miRNAs are loaded into AGO proteins, and act upon highly or perfectly complementary targets by promoting their cleavage or repressing translation (Llave et al., 2002b; Rhoades et al., 2002; Chen, 2004). Most miRNAs are 21-nt long and are generally loaded into AGO1 that has both a small RNA-binding PAZ domain and a catalytic PIWI domain, and mediates miRNA-guided cleavage of complementary target transcripts (Vaucheret et al., 2004; Baumberger \& Baulcombe, 2005). Opposite to what was known for animals, in 2005 Baumberger and Baulcombe reported that immunoprecipitation assays suggested that AGO1 alone could be enough for RNA induced silencing mechanisms in plants. Recently, however, Hsp90, a chaperone involved in protein folding, was co-purified with AGO1 (Iki et al., 2010), suggesting these two proteins could be part of a plant RNA silencing complex. In the same work, Hsp90 was found to be required for the loading of sRNAs into AGO1, presumably by inducing conformational changes in this protein (Iki et al., 2010).

There are also other miRNAs that are processed into 22-nt molecules, a process that is thought to be related to asymmetry in the hairpin precursor that is cleaved into a 22-nt mature miRNA and a 21-nt miRNA* (Cuperus et al., 2010). Recently, these molecules that are also loaded into AGO1 were found to trigger the production of secondary sRNAs from the 3' product of miRNA-directed cleavage (Chen et al., 2010; Cuperus et al., 2010).

\subsection{Small interfering RNAs}

A second and less studied group of sRNAs is known to exist in plants. These molecules, generally called siRNAs, are cleaved by DCL proteins from long dsRNA molecules that do not form hairpins (Carrington \& Ambros, 2003). These are produced by either the transcription of inverted repeats or by the action of RNA-dependent RNA polymerases (RDRs) that convert single-stranded RNA transcripts into dsRNA (Dalmay et al., 2000).

The best studied siRNAs in plants fall into two distinct categories: RDR2-dependent (or heterochromatin associated) siRNAs (Fig.1B) and trans-acting siRNAs (ta-siRNAs, Fig.1C) (Ramachandran \& Chen, 2008).

The first sub-group comprises siRNAs that are transcribed by RNA polymerase IV (Pol IV) and further processed to dsRNA by RDR2 (Herr et al., 2005). These sRNAs are mostly cleaved into 24-nt duplexes by DCL3 (Gasciolli et al., 2005) and loaded into AGO4 to guide target silencing, usually by promoting DNA or histone methylation (Zilberman et al., 2003; Herr et al., 2005).

The other sub-group, gathers the small RNAs that act upon transcripts that are very different from the genes that originated them (Vazquez et al., 2004). The biogenesis of these ta-siRNAs requires miRNA-AGO1-mediated cleavage of target transcripts, called TAS genes (Allen et al., 2005; Allen \& Howell, 2010), and seems to be related to the production of 22-nt miRNAs (Chen et al., 2010; Cuperus et al., 2010). The RNA polymerase RDR6, together with SUPRESSOR OF GENE SILENCING 3 (SGS3) protein, processes the cleavage products (Vazquez et al., 2004; Montgomery et al., 2008b), yielding long dsRNA molecules that are subjected to DCL4-mediated phased cleavage of 21-nt dsRNA duplexes (Gasciolli et al., 2005; Yoshikawa et al., 2005). One of the strains from each of these duplexes is then loaded into an AGO protein, according to the criteria previously mentioned, in order to promote the silencing of target transcripts (Mi et al., 2008). Four TAS genes have been identified in 
arabidopsis: TAS1, TAS2 (both targeted by miR173) (Montgomery et al., 2008b), TAS3 (cleaved by miR390) (Allen et al., 2005) and TAS4 (targeted by miR828) (Rajagopalan et al., 2006). Interestingly, TAS3 seems to undergo a specific pathway that is conserved in several plant species and different from what is observed for other TAS genes. This pathway depends on miR390, a 21-nt long conserved miRNA, and requires AGO7 to be bound to the miRNA in order to cleave TAS3 transcripts (Adenot et al., 2006; Montgomery et al., 2008a).

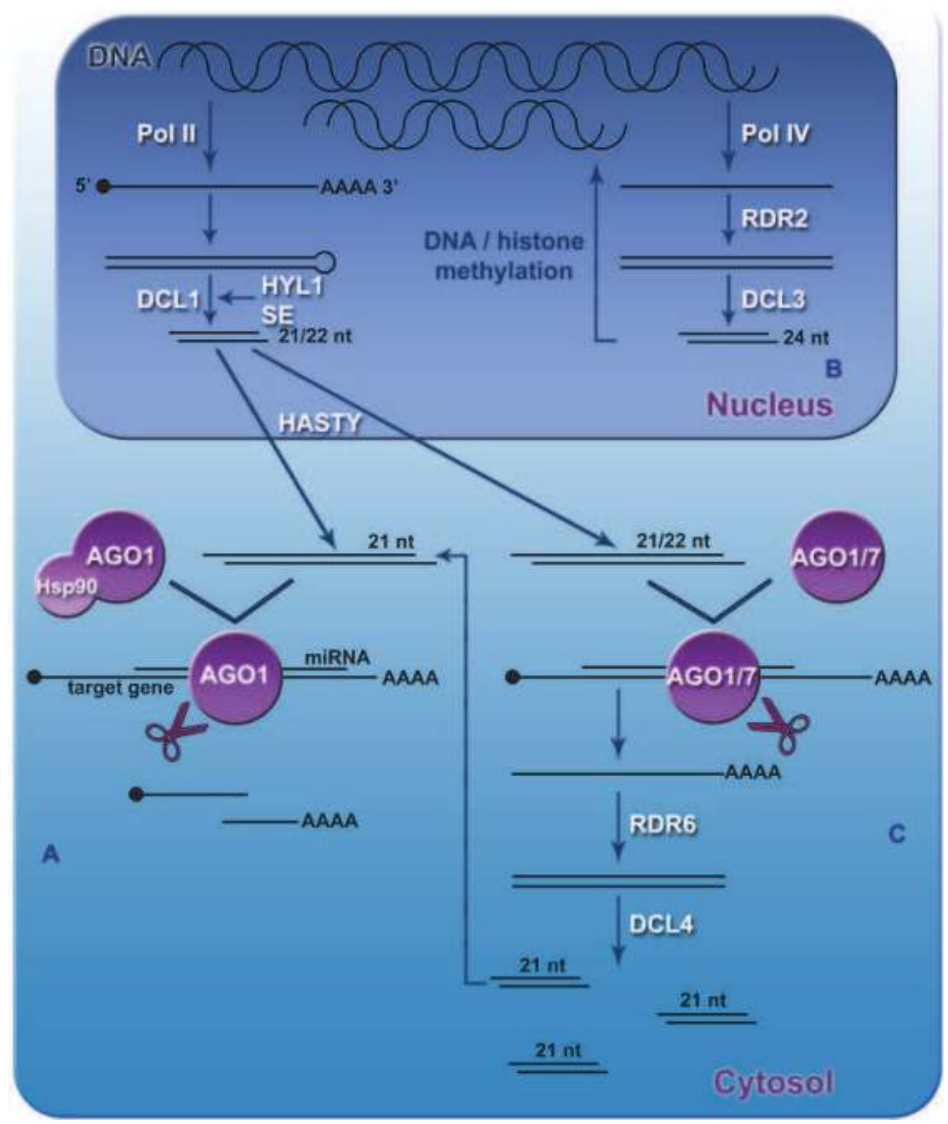

Fig. 1. Biosynthesis and action of the main classes of plant small RNAs. miRNAs are synthesized from stem loop precursors transcribed by Pol II, like protein-coding genes. Most 21-nt miRNAs are loaded into AGO1 and act upon target mRNAs in a sequence dependent manner, by either promoting their cleavage (A) or repressing translation (not represented). In the nucleus, siRNAs are synthesized from long dsRNA precursors, transcribed by Pol IV. These small RNAs are mainly loaded into AGO3 and are known to be involved in DNA and histone methylation (B). 22-nt long miRNAs are also loaded into AGO1. However, together with miR390, which is 21-nt long and is loaded into AGO7, these miRNAs trigger the biosynthesis of ta-siRNAs by DCL4. The newly formed siRNAs will be loaded into AGO1 and, like miRNAs, promote target cleavage (C). 


\section{Small RNAs and abiotic stress}

A large portion of already identified miRNAs are present in several plant species (Reinhart et al., 2002; Bonnet et al., 2004; Wang et al., 2004). Most of these conserved miRNAs are known to have key roles in plant development, targeting a variety of transcription factors (TFs) related to pattern formation and organ differentiation (Llave et al., 2002b; Rhoades et al., 2002; Carrington \& Ambros, 2003; Todesco et al., 2010). Lately, however, with highthroughput sequencing techniques becoming more and more accessible, several miRNAs (and other sRNAs) have been identified that seem to be family or species-specific and can be involved in many other processes in plants (Bonnet et al., 2004; Moxon et al., 2008; Szittya et al., 2008; Schreiber et al., 2011; Song et al., 2011). In fact, as the knowledge on small RNAs has broadened and new targets have been identified, it became apparent that, apart from their role in plant development, sRNAs are also involved in other processes in plants (JonesRhoades \& Bartel, 2004; Sunkar \& Zhu, 2004).

Since the early 2000's, several reports have associated sRNAs to abiotic stress responses, showing that post-transcriptional regulation of gene expression plays an important role in these phenomena (reviewed by Covarrubias \& Reyes, 2010). The fact that plant miRNAs target transcripts in a sequence-specific manner, allowed Jones-Rhoades and Bartel (2004) to computationally predict targets for a conserved group of these riboregulators. In this work, the authors found that the expression of miR395 depends on sulfate availability, and that some other miRNAs can target transcripts that are potentially involved in responses to abiotic stress (Jones-Rhoades \& Bartel, 2004). By then, Sunkar and Zhu (2004), analysed two week-old arabidopsis seedlings, and identified a variety of conserved miRNAs that were differentially expressed upon cold, dehydration, $\mathrm{NaCl}$ and $\mathrm{ABA}$ treatments. The authors found that, for instance, miR393, miR397b and miR402 were up-regulated in all the implemented conditions. On the other hand, miR389a, which was later found to be related to ta-siRNAs (Allen \& Howell, 2010), was down-regulated under all stresses (Sunkar \& Zhu, 2004).

Recently, Amor and co-workers (2009) analysed a group of arabidopsis long non-protein coding RNAs (npcRNAs), and found that 22, out of 76, showed differential expression upon water deficit, phosphate starvation and $\mathrm{NaCl}$ treatment. Interestingly, these npcRNAs are thought to regulate gene expression in either this long form, or by being precursors for siRNAs and miRNAs (Amor et al., 2009). Moreover, changes in DNA and histone methylation, processes that can be regulated by siRNAs, are known to occur in plants subjected to adverse conditions (Chinnusamy \& Zhu, 2009). In fact, it was recently found that in arabidopsis stress-induced transgenerational global genome methylation, and consequent induced stress tolerance, is impaired in dcl2 dcl3 mutants (Boyko et al., 2010). Together, these observations show that, besides miRNAs, other sRNAs can also be involved in responses to environmental stimuli in plants.

In the following sections we will summarize some of the most important results obtained in this field.

\subsection{Osmotic stress: Water deprivation, salinity and abscisic acid}

Water deprivation and salt stress alter the osmotic balance inside the cells, and considerable crosstalk is known to exist between responses to both conditions (Table 1) (Shinozaki \& Yamaguchi-Shinozaki, 2007). Stomata closure, reduction in cell growth and photosynthesis and higher respiration rates are all general phenomena that can be observed in plants 
subjected to osmotic stress (Shinozaki \& Yamaguchi-Shinozaki, 2007). Moreover, changes are also registered at the cellular and molecular levels, and several proteins and osmolytes are known to accumulate inside the cells to overcome osmotic changes (Shinozaki \& Yamaguchi-Shinozaki, 2007).

In 2007, Zhao and co-workers analyzed the expression of a set of rice miRNAs from seedlings subjected to dehydration stress, induced by PEG treatment, and found that miR169g, miR393 and miR397b were up-regulated in these conditions. Recently, both miR169 and miR393 were also found to be induced by different concentrations of PEG in tobacco (Frazier et al., 2011). However, miR169 was shown to be down-regulated in adult rice plants after water withholding for several days (Zhou et al., 2010), suggesting that sRNA regulation depends on several factors, like the developmental stage and how a certain stress is imposed (Jia et al., 2009b). On the other hand, Zhao and co-workers (2007) showed that, among the miR169 family members, only miR169g seemed to be induced by PEG. In fact, it has been reported that different members of the same miRNA family are often regulated in different ways upon a certain stimuli (Lu et al., 2008). Therefore, it may also be possible, that in both works, different miRNAs were analysed that have distinct expression profiles under similar conditions.

Members of the miR169 family, have also been shown to be induced under high salinity conditions in both arabidopsis and rice (Zhao et al., 2009), and miR393 was also induced after treatment with $\mathrm{ABA}$ and $\mathrm{NaCl}$ in common bean (Phaseolus vulgaris; Arenas-Huertero et al., 2009). These observations suggest that these miRNAs can be involved in general responses to osmotic stress.

The elements of the miR169 family are known to target CCAAT-box Binding Factors (Rhoades et al., 2002), some of which have been shown to be involved in water deficit tolerance in maize (Nelson et al., 2007). However, these TFs were identified in maize as positive regulators of these responses, and their over-expression was shown to improve tolerance to water deprivation and increased yield (Nelson et al., 2007). Therefore, a reduction in the expression of miR169 should be expected in these conditions, and in most cases the opposite is observed. Further studies are necessary to unveil the relation between miR169 and CCAAT-box Binding Factors and their role in responses to osmotic stress.

MiR393, on the other hand, is known to target TRANSPORT INHIBITOR RESPONSE1 (TIR1) transcripts, which are involved in auxin signalling pathways (Jones-Rhoades \& Bartel, 2004). MiR393-mediated down-regulation of TIR1 under stress conditions could result in reduced hypocotyl elongation and lateral root growth, as observed in tir1 mutants (Ruegger et al., 1998). Strikingly, miR393 was also shown to be induced upon Pseudomonas syringae infection and repress bacterial growth, thus establishing a relation between responses to both biotic and abiotic stress conditions (Navarro et al., 2006).

In barrel medic (Medicago truncatula), we have shown that miR408 is highly up-regulated in both shoots and roots of adult plants subjected to water deprivation for one week (Fig. 2) (Trindade et al., 2010). This up-regulation was also recently observed in barley (Hordeum vulgare) leaves after dehydration treatment for $4 \mathrm{~h}$ and $8 \mathrm{~h}$ (Kantar et al., 2010). MiR408 is known to target plantacyanin-like transcripts in several species, hence it has been related to the control of copper homeostasis in plants (Abdel-Ghany \& Pilon, 2008; Trindade et al., 2010). Therefore, it seems that there may be a relation between the reduction of water uptake and copper deficiency, although further studies are needed to confirm this hypothesis.

Despite the intensive crosstalk observed in responses to water deficit and salt stress, not all miRNAs seem to be involved in pathways that are common to both. For instance, different 
concentrations of $\mathrm{NaCl}$ down-regulated the expression of miR159 and miR167, and induced the expression of miR172 and miR396 in tobacco (Nicotiana tabacum) plants (Frazier et al., 2011). On the other hand, these miRNAs were induced after treatment with different concentrations of PEG, in plants grown in the exact same conditions (Frazier et al., 2011). Interestingly, when compared to control plants, most miRNAs exhibited higher differences upon treatment with lower PEG concentrations, than with higher concentrations (Frazier et al., 2011). This observation suggests that miRNAs could be involved mainly in early responses to abiotic stress conditions, like reported for some TFs ( $\mathrm{Zhu}, 2002)$.

Several water deficit and high salinity-responsive genes are also differentially expressed upon treatments with exogenous abscisic acid (ABA; Table 1) (Zhu, 2002; Nakashima et al., 2009). In fact, it is widely known that responses to osmotic stress comprise both ABAdependent and ABA-independent pathways (Bohnert \& Sheveleva, 1998; Nakashima et al., 2009). For instance, the expression of miR159 was shown to be induced by ABA and drought in arabidopsis, regulating abiotic stress responses in germinating seedlings (Reyes \& Chua, 2007).

Moreover, dehydration-responsive elements (DREs) and abscisic acid responsive elements (ABREs), known to be present in the promoter region of water deficit and high salinityinducible genes (Nakashima et al., 2009), have been identified in the region upstream of several rice MIR169 genes (Zhao et al., 2007; Zhao et al., 2009). This observation suggests that, besides regulating a large number of TFs, miRNAs can themselves be regulated at the

\begin{tabular}{|c|c|c|c|}
\hline miRNA & Regulation & Target transcripts & References \\
\hline \multirow{3}{*}{ miR159 } & $\uparrow$ water deficit & \multirow{3}{*}{ МҮB101, МҮB33 } & \multirow{3}{*}{$\begin{array}{l}\text { Reyes \& Chua (2007) } \\
\text { Frazier et al. (2011) }\end{array}$} \\
\hline & $\uparrow \mathrm{ABA}$ & & \\
\hline & $\downarrow \mathrm{NaCl}$ & & \\
\hline miR165/166 & $\uparrow$ cold & $\begin{array}{l}\text { PHABULOSA, homeobox } \\
\text { genes }\end{array}$ & $\begin{array}{l}\text { Zhou et al. (2008); Lv } \\
\text { et al. (2010) }\end{array}$ \\
\hline \multirow{2}{*}{$\operatorname{miR} 167$} & $\uparrow$ water deficit & & \multirow{2}{*}{ Frazier et al. (2011) } \\
\hline & $\downarrow \mathrm{NaCl}$ & & \\
\hline \multirow{2}{*}{$\operatorname{miR} 168$} & $\uparrow$ water deficit & \multirow{2}{*}{ ARGONAUTE 1} & Liu et al. (2008) \\
\hline & $\uparrow \mathrm{NaCl}$ & & \multirow{5}{*}{$\begin{array}{l}\text { Zhao et al. (2007); } \\
\text { Zhao et al. (2009); } \\
\text { Zhou et al. (2010); } \\
\text { Frazier et al. (2011) }\end{array}$} \\
\hline \multirow{4}{*}{$\operatorname{miR} 169$} & $\downarrow \quad$ water & & \\
\hline & & & \\
\hline & $\uparrow$ PEG treatment & C CAA 1-Dox DInaing Factors & \\
\hline & $\uparrow \mathrm{NaCl}$ & & \\
\hline
\end{tabular}




\begin{tabular}{|c|c|c|c|}
\hline miRNA & Regulation & Target transcripts & References \\
\hline $\operatorname{miR} 171$ & $\begin{array}{l}\uparrow \text { water deficit } \\
\uparrow \mathrm{NaCl}\end{array}$ & SCARECROW-like & Liu et al. (2008) \\
\hline $\operatorname{miR} 172$ & $\begin{array}{l}\uparrow \text { water deficit } \\
\uparrow \mathrm{NaCl} \\
\uparrow \text { cold }\end{array}$ & APETALA2 & Frazier et al. (2011) \\
\hline $\operatorname{miR393}$ & $\begin{array}{l}\uparrow \text { water deficit } \\
\uparrow \mathrm{ABA} \\
\uparrow \mathrm{NaCl} \\
\uparrow \text { cold }\end{array}$ & $\begin{array}{l}\text { TRANSPORT INHIBITOR } \\
\text { RESPONSE1 }\end{array}$ & $\begin{array}{l}\text { Sunkar \& Zhu (2004); } \\
\text { Zhao et al. (2007); } \\
\text { Arenas-Huertero et } \\
\text { al. (2009); Frazier et } \\
\text { al. (2011); }\end{array}$ \\
\hline $\operatorname{miR396}$ & $\begin{array}{l}\uparrow \text { water deficit } \\
\uparrow \mathrm{NaCl} \\
\uparrow \text { cold }\end{array}$ & $\begin{array}{l}\text { GROWTH REGULATING } \\
\text { FACTOR }\end{array}$ & $\begin{array}{l}\text { Liu et al. (2008); } \\
\text { Frazier et al. (2011) }\end{array}$ \\
\hline $\operatorname{miR397b}$ & $\begin{array}{l}\uparrow \text { water deficit } \\
\uparrow \mathrm{ABA} \\
\uparrow \mathrm{NaCl} \\
\uparrow \text { cold }\end{array}$ & Laccases & $\begin{array}{l}\text { Sunkar \& Zhu (2004); } \\
\text { Zhao et al. (2007); }\end{array}$ \\
\hline $\operatorname{miR398}$ & $\begin{array}{l}\uparrow \text { water deficit } \\
\uparrow \mathrm{ABA} \\
\uparrow \mathrm{NaCl}\end{array}$ & $\begin{array}{l}\text { COPPER SUPEROXIDE } \\
\text { DISMUTASE, } \\
\text { CYTHOCHROME C OXIDASE } \\
\text { SUBUNIT V }\end{array}$ & $\begin{array}{l}\text { Jia et al. (2009a); } \\
\text { Trindade et al. (2010) }\end{array}$ \\
\hline $\operatorname{miR} 402$ & $\begin{array}{l}\uparrow \text { water deficit } \\
\uparrow \mathrm{ABA} \\
\uparrow \mathrm{NaCl} \\
\uparrow \text { cold }\end{array}$ & ARGONAUTE 2 & Sunkar \& Zhu (2004); \\
\hline $\operatorname{miR} 408$ & $\uparrow$ water deficit & PLANTACYANIN & $\begin{array}{l}\text { Trindade et al. } \\
\text { (2010); Kantar et al. } \\
\text { (2010) }\end{array}$ \\
\hline $\operatorname{miR} 2118$ & $\begin{array}{l}\uparrow \text { water deficit } \\
\uparrow \mathrm{ABA}\end{array}$ & unknown & $\begin{array}{l}\text { Arenas-Huertero et } \\
\text { al. (2009) }\end{array}$ \\
\hline
\end{tabular}

$\uparrow$ indicates up-regulation; $\downarrow$ indicates down-regulation.

Table 1. Conserved miRNAs involved in responses to osmotic and cold stress. 
transcriptional level. Interestingly, the over-expression of miR169c in tomato was reported to improve drought tolerance through a reduction in stomata aperture, a process that is controlled by $\mathrm{ABA}$, and consequent reduction of transpiration and leaf water losses (Chinnusamy et al., 2008; Zhang et al., 2011b).

Non-conserved miRNAs have also been reported to be involved in responses to osmotic stress (Table 2). In common bean, the legume-specific miR1514a and miR2119, and the conserved miR2118 were up-regulated upon water deficit and ABA treatments (ArenasHuertero et al., 2009). Interestingly, miR1514a was predicted to target transcripts for Mnsuperoxide dismutase (SOD) and a cysteine protease, while miR2119 was predicted to cleave Aldehyde Dehydrogenase 1 and zinc finger protein mRNAs, among others, (ArenasHuertero et al., 2009), supporting the hypothesis of their involvement in responses to different types of stresses. Recently, the grass-specific miR1432 and miR1867 (predicted to target phenylalanine tRNA synthetase and a protein from the DUF1242 superfamily, respectively) were also shown to be induced by dehydration in roots and shoots of wild emmer wheat (Triticum turgidum ssp. dicoccoides), respectively (Kantar et al., 2011).

Besides miRNAs, other sRNAs have been shown to have a role in osmotic stress responses. For instance, Borsani and co-workers (2005) identified in arabidopsis a new group of plant siRNAs, known as natural antisense siRNAs (nat-siRNAs), that is formed from overlapping genes (Borsani et al., 2005). Their biogenesis, requires DCL2, RDR6, SGS3 and Pol IV to generate a 24-nt nat-siRNA from D1-pyroline-5-carboxylate dehydrogenase (P5CDH) cleavage, that will set the phase for subsequent cleavage by DCL1 of 21-nt nat-siRNAs from the same transcript (Borsani et al., 2005). In the same work, the authors found that the expression of SRO5 (a transcript of unknown function) is required for the production of natsiRNAs and that it is induced upon salt treatment. This mechanism represents a unique regulation of salt stress responses, because cleavage of $\mathrm{P} 5 \mathrm{CDH}$ leads to accumulation of proline (improving salt tolerance) and reactive oxygen species (ROS), an effect that is counteracted by SRO5 (Borsani et al., 2005). Moreover, the authors mention that they have identified a variety of other siRNAs synthesized from overlapping genes that were only identified under certain abiotic stress conditions, implying that these molecules could have a more generalized role in the responses to environmental constrains.

\subsection{Cold stress}

Cold stress generally leads to a reduction in metabolic rates and water availability, due to chilling-induced inhibition of absorption (Chinnusamy et al., 2007). Therefore, it is not surprising that crosstalk between water deficit, salt stress and cold has been reported (Table 1) (Bohnert \& Sheveleva, 1998).

As for other stress conditions, post-transcriptional regulation of gene expression also plays an important role in response to low temperatures (Chinnusamy et al., 2007), and alternative-splicing in particular is known to have an important role under cold stress conditions (Iida et al., 2004).

In 2008, miR168, miR171 and miR396 were shown to be induced by drought, cold and salt stress in arabidopsis seedlings (Liu et al., 2008), suggesting that miRNAs can be involved in the pathways common to all these stimuli. Following this, Zhou and co-workers (2008) identified four arabidopsis MIRNA genes that are inducible by cold stress, using a computational approach based on transcriptome and promoter analysis data, coupled with experimental validation. Northern blot analysis revealed that miR165/miR166, miR169 and 
miR172 were also up-regulated upon cold treatment (Zhou et al., 2008). Some elements of the miR166 family were also found to be up-regulated in similar conditions in rice, while miR168, miR169 and miR171 showed opposite expression profiles (Lv et al., 2010). These observations show once again that miRNA expression upon abiotic stress can be complex and depend on a variety of parameters. Interestingly, most of these conserved coldregulated miRNAs are known to target TFs with known roles in plant development (JonesRhoades \& Bartel, 2004), suggesting that miRNA-mediated responses to this kind of stress could be mainly at the structural level.

\begin{tabular}{|c|c|c|c|c|}
\hline miRNA & Regulation & Predicted target transcript & $\begin{array}{l}\text { Other } \\
\text { species }\end{array}$ & References \\
\hline $\begin{array}{l}\text { pvu- } \\
\text { miR1514a }\end{array}$ & $\begin{array}{l}\uparrow \text { water deficit } \\
\uparrow \mathrm{ABA}\end{array}$ & $\begin{array}{l}\text { MnSOD, } \\
\text { CYSTEINE PROTEASE }\end{array}$ & soybean & $\begin{array}{l}\text { Arenas-Huertero et } \\
\text { al. (2009) }\end{array}$ \\
\hline pvu-miR2119 & $\begin{array}{l}\uparrow \text { water deficit } \\
\uparrow \mathrm{ABA}\end{array}$ & $\begin{array}{l}\text { ALDEHYDE } \\
\text { DEHYDROGENASE1, } \\
\text { Zinc finger domain }\end{array}$ & $\begin{array}{l}\text { soybean; } \\
\text { barrel medic }\end{array}$ & $\begin{array}{l}\text { Arenas-Huertero et } \\
\text { al. (2009) }\end{array}$ \\
\hline$t t u$-miR1432 & $\begin{array}{l}\uparrow \text { water deficit } \\
\uparrow \mathrm{ABA}\end{array}$ & $\begin{array}{l}\text { PHENYLALANINE } t R N A \\
\text { SYNTHETASE }\end{array}$ & $\begin{array}{l}\text { rice, maize, } \\
\text { sorghum }\end{array}$ & Kantar et al. (2011) \\
\hline ttu-miR1867 & $\begin{array}{l}\uparrow \text { water deficit } \\
\uparrow \mathrm{ABA}\end{array}$ & DUF1242 & rice & Kantar et al. (2011) \\
\hline osa-miR1320 & $\downarrow$ cold stress & $\begin{array}{l}\text { Clathrin assembly, } \\
\text { FUCOSYLTRANSFERASE7, } \\
\text { REMORIN }\end{array}$ & ------ & Lv et al. (2010) \\
\hline osa-miR1435 & $\begin{array}{l}\uparrow \text { late cold } \\
\text { stress }\end{array}$ & $\begin{array}{l}\text { B3 DNA Binding domain, } \\
\text { UDP } \\
\text { GLUCOSYLTRANSFERASE }\end{array}$ & sorghum & Lv et al. (2010) \\
\hline osa-miR1876 & $\downarrow$ cold stress & HISTONE DEACETYLASE6 & ------ & Lv et al. (2010) \\
\hline osa-miR1884 & $\downarrow$ cold stress & $\begin{array}{l}\text { ATPase, } \\
\text { URICASE, } \\
\text { ABA stress-ripening, } \\
\text { TMV response-related }\end{array}$ & ----- & Lv et al. (2010) \\
\hline osa-miR1850 & $\begin{array}{l}\uparrow \text { oxidative } \\
\text { stress }\end{array}$ & unknown & ------ & Li et al. (2010) \\
\hline $\begin{array}{l}\text { ptc- } \\
\operatorname{miR} 475 \mathrm{a}, \mathrm{b}\end{array}$ & $\begin{array}{l}\downarrow \text { early cold } \\
\text { stress }\end{array}$ & Pentatricopeptide repeat & ----- & Lu et al. (2008) \\
\hline ptc-miR476a & $\downarrow$ cold stress & Pentatricopeptide repeat & ----- & Lu et al. (2008) \\
\hline
\end{tabular}

$\overline{p v u \text { - common bean; } t t u \text { - wild emmer wheat; osa- rice; } p t c \text { - black cottonwood. } \uparrow \text { indicates up-regulation; } \downarrow}$ indicates down-regulation.

Table 2. Non-conserved miRNAs involved in responses to abiotic stress in plants. 
A deeper look into the promoter region of some cold-inducible MIRNA genes, revealed an abundance of motifs that are known to be involved in responses to cold, namely W-box (TTGAC), ABRE-core (ACGTGG/TC) and LTRE-core (A/GCCGAC) (Zhou et al., 2008). This observation supports once again the idea that stress-responsive miRNAs can be regulated at the transcriptional level.

Like previously reported for water deficit and salt stress, non-conserved miRNAs are also involved in cold stress responses in plants (Table 2). For instance, a set of rice miRNAs, namely miR1435, miR1876, miR1320, and miR1884, not previously detected in arabidopsis, were recently found to be differentially expressed upon cold treatment ( $\mathrm{Lv}$ et al., 2010). Moreover, in black cottonwood (Populus trichocarpa) the species-specific miR475a,b and miR476a, both predicted to target transcripts coding for pentatricopeptide repeat-containing proteins (PPRs), were shown to be down-regulated in similar conditions ( $\mathrm{Lu}$ et al., 2008). Interestingly, PPRs were identified in arabidopsis as RNA-binding proteins that seem to be involved in post-transcriptional regulation in mitochondria and chloroplasts (Lurin et al., 2004), suggesting sRNAs can also regulate organelle metabolism.

\subsection{Flooding and hypoxia}

Flooding can also severely compromise plant growth and productivity, since it is associated to a reduction of oxygen availability to the cells (Licausi, 2010).

The expression of some maize miRNAs was found to be induced after submergence (Zhang et al., 2008b). Strikingly, it seems that different miRNAs are regulated at different time points and in most cases this induction is transient. For instance, miR166, miR167 and miR171 were induced in the early stages, while the expression of miR159 was reduced by this time and further induced after 24h of submergence (Zhang et al., 2008b). Most of these miRNAs were shown to have cis-acting elements in their promoter regions that are associated with anaerobic stress, namely AREs (anaerobic responsive elements) and GCmotifs (Zhang et al., 2008b). A member of the miR167 family was also up-regulated in submerged arabidopsis plants, together with elements from the miR156, miR157, miR158, miR161, miR169, miR172, miR391, miR395 and miR775 families (Moldovan et al., 2010). With the exception of miR172, all the other miRNAs exhibited similar expression patterns upon treatment for mitochondrial inhibition, suggesting they are actually hypoxia-inducible miRNAs (Moldovan et al., 2010).

Like previously observed for osmotic stress, other sRNAs can be involved in responses to oxygen deprivation. Recently, Moldovan and co-workers (2010) have shown that several tassiRNAs derived from the TAS1, TAS2 and TAS3 loci are also up-regulated in arabidopsis under hypoxia conditions.

\subsection{UV radiation and light}

According to some recent reports, miRNAs can also be involved in responses to light and radiation stimuli. Zhou and co-workers (2007) gathered data from promoter element analysis and the expression of protein-coding genes predicted to be targeted by miRNAs, and identified in silico a group of potentially UV-B inducible arabidopsis miRNAs. Later, using a home-made array, Jia and co-workers (2009) identified miRNAs in black cottonwood that were differentially expressed upon $2 \mathrm{~h}$ of treatment with the same radiation. As previously predicted for arabidopsis (Zhou et al., 2007), miR156, miR160, 
miR165/166, miR167 and miR398 were induced in these conditions, whereas the same pattern was not observed for miR159 and miR393 in both species (Jia et al., 2009a). Moreover, miR169, miR395 and miR472 were down-regulated by UV-B radiation, while the opposite was observed for miR168, miR398 and miR408 (Jia et al., 2009a). These results show that, although several miRNAs are conserved among plant species, their regulation upon certain stimuli can actually be different.

Also, in both arabidopsis and common aspen (Populus tremula), the majority of the selected miRNAs exhibited stress and light-inducible cis-acting elements, like GT-1 site (GGTTAA) and I-boxes (GATAAGA), upstream of their coding genes (Zhou et al., 2007; Jia et al., 2009a). Besides being regulated by UV radiation, some miRNAs also seem to be regulated by the photoperiod. For instance, miR167, miR168, miR171 and miR393 were shown to accumulate during the light period in arabidopsis (Sire et al., 2009). This expression pattern was absent in plants grown under continuous light, showing that these miRNAs were actually induced by light and not by the circadian clock (Sire et al., 2009).

\subsection{Oxidative stress}

In plants, oxidative stress usually emerges as a secondary effect of other stress conditions and is highly responsible for losses in crop productivity (Bartels \& Sunkar, 2005; Sunkar et al., 2006). To overcome the higher production of ROS upon stress stimuli, plants have developed enzymatic and non-enzymatic detoxification strategies (Bohnert \& Sheveleva, 1998), and during the last decade, several works have reported the involvement of sRNAs in these mechanisms.

In an attempt to mimic oxidative stress, $\mathrm{Li}$ and co-workers (2010) treated rice seedlings with different concentrations of $\mathrm{H}_{2} \mathrm{O}_{2}$, and found that the conserved miR169, miR397 and miR827 were up-regulated in these conditions, while miR319a and miR528 were down-regulated. Moreover, the authors identified a rice-specific miRNA, miR1850, that was induced by the applied stress ( $\mathrm{Li}$ et al., 2010), providing extra evidence to the involvement of miRNAs in both general and species-specific mechanisms of abiotic stress response.

The expression of miR398 has been shown to be repressed upon oxidative stress (Sunkar et al., 2006; Jagadeeswaran et al., 2009), and, as expected, it is down-regulated under several adverse conditions, like salt stress, ozone fumigation and even infection with Pseudomonas syringae (Jagadeeswaran et al., 2009). Besides, targeting cytochrome c oxidase (Jones-Rhoades \& Bartel, 2004; Trindade et al., 2010), this miRNA is known to target both cytosolic and plastidic Cu/Zn superoxide dismutases (CSD1 and CSD2, respectively) (Jones-Rhoades \& Bartel, 2004; Sunkar et al., 2006), that are responsible for the conversion of $\mathrm{O}_{2}{ }^{-}$to $\mathrm{H}_{2} \mathrm{O}_{2}$ (Kliebenstein et al., 1998). Therefore the reduction in the levels of miR398, leads to an increase in CSD transcripts, thus protecting the cells against oxidative damage (Sunkar et al., 2006).

However, the expression of miR398 is not always decreased under abiotic stress conditions. In adult barrel medic plants subjected to water deficit for one week, this miRNA was highly up-regulated in both shoots and roots (Fig. 2) (Trindade et al., 2010), a result that was also recently observed in both PEG-treated tobacco (Frazier et al., 2011) and dehydrated wild emmer wheat (Kantar et al., 2011). A similar expression profile had previously been observed after sucrose addition in arabidopsis (Dugas \& Bartel, 2008) and in common aspen subjected to short time treatments with $\mathrm{ABA}, \mathrm{NaCl}$ and UV-B radiation (Jia et al., 2009a). Interestingly, it was recently shown that the expression of this miRNA not only depends on the type of stress imposed, but it also seems to oscillate with the degree of stress (Frazier et al., 2011). 


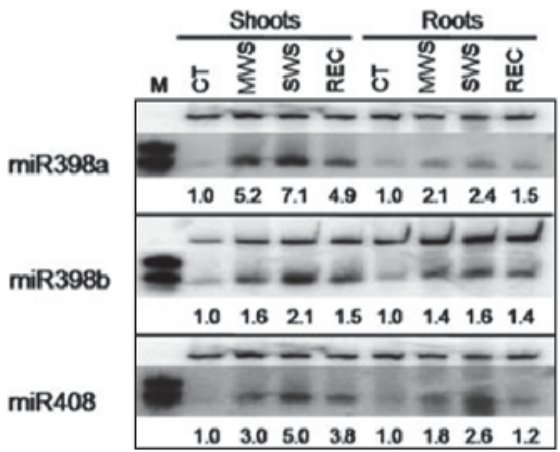

Fig. 2. Northern blot analysis of the expression of miR398a, miR398b and miR408 in both shoots and roots of 8 week-old Medicago truncatula plants subjected to different degrees of water deficit: CT- control; MWS - moderate water deficit; SWS- severe water deficit; RECrecovery; M-microRNA size marker from New England Biolabs (the darker bands correspond to 24 and $21 \mathrm{nt}$ ). Small nuclear RNA U6 was used as a loading control (Trindade et al., 2010).

Besides having a role in response to oxidative stress, miR398, along with other miRNAs, has been associated to the maintenance of copper homeostasis in plants (Abdel-Ghany \& Pilon, 2008). Overall these results seem to suggest that this miRNA can be regulated in opposite ways by at least two distinct pathways in order to protect the cells from damage. One pathway seems to be dependent on the copper status of the plant, while the other seems to be related to oxidative stress. Some authors have hypothesized that the induction of miR398, and consequent degradation of transcripts of copper proteins, could be a way of saving copper for vital proteins like plastocyanin, known to be involved in the electron transport chain of the photosynthetic pathway (Abdel-Ghany \& Pilon, 2008). According to Dugas and Bartel (2008), the induction of this miRNA, and further reduction of CSD transcripts, under these conditions could be caused by a reduction in ROS production as a consequence of some photosynthetic impairment. It could also be that different MIR398 genes are being regulated in different ways, like previously proposed for MIR159 (Reyes \& Chua, 2007). A deeper analysis on the expression pattern and the promoter regions of each miR398 family member could shed some light on this matter.

\subsection{Hormone signalling}

Plant hormones are also known to play a role in abiotic stress responses. As mentioned above, many genes that have been shown to be induced by drought, salt stress and cold are also regulated upon exogenous ABA treatments (Zhu, 2002).

Besides ABA, other phytohormones like auxins, cytokinins, gibberellins, among others, can also be directly or indirectly involved in responses to environmental stimuli. Over the last years, several reports have shown that some sRNAs can be involved in these signalling pathways, either by being regulated by these hormones, or by targeting hormoneresponsive transcripts (Guo et al., 2005; Reyes \& Chua, 2007). In 2005, Sorin and co-workers reported that ago1 mutants were practically unable to form adventitious roots and that this abnormal development was related to impairment in the auxin metabolism, suggesting an 
involvement of miRNAs in these processes (Sorin et al., 2005). Previously, it had also been shown that hyl1 mutants exhibited altered sensitivity to different hormone treatments (Lu \& Fedoroff, 2000). Additionally, some abiotic stress-inducible miRNAs exhibit hormoneresponsive cis-acting elements, like ABRE, gibberellic acid (GA3)-responsive element (GARE), methyl jasmonate-responsive element (CGTCA motif) and salicylic acid-responsive element in their promoter regions (Liu et al., 2009; Lv et al., 2010). Taken together, these data strongly suggest that there is an involvement of plant hormones in sRNA-mediated responses to abiotic stress in plants.

Auxins, for instance, were recently shown to participate in responses to salt and oxidative stresses in arabidopsis through regulation of the redox metabolism, in which TIR1 and AFB2 auxin receptors, known to be targeted by miR393 (Jones-Rhoades \& Bartel, 2004), seem to be involved (Iglesias et al., 2010). Also, some light and cold-inducible miRNAs are known to be involved in the regulation of auxin signalling pathways (Zhou et al., 2007; Zhou et al., 2008). In rice, miR167 and miR169 were down-regulated by ABA and miR168 and miR169 were down and up-regulated, respectively, after auxin treatment (Liu et al., 2009). miR167 is known to target ARF6 and ARF8, which are regulators of female and male reproduction (Wu et al., 2006). These observations led to the hypothesis that ABA-induced downregulation of this miRNA could be related to early reproduction, a phenomenon that is generally observed in plants subjected to stress conditions (Liu \& Chen, 2009). Moreover, there seems to be a relation between auxin and ABA signalling pathways, in which miR167 is apparently involved. Also, miR319 was shown to be up-regulated by both $\mathrm{GA}_{3}$ and ABA, and down-regulated by cytokinins (Liu et al., 2009), suggesting that miRNAs can be involved in processes of crosstalk between different phytohormones and between those and abiotic stress conditions.

Upon certain stress stimuli, plants can respond by altering their growth and development, in order to avoid or reduce stress-inducible damage. Auxins are known to be involved in the regulation of plant development, and could play an important role in these mechanisms (reviewed by Vanneste \& Friml, 2009). For instance, the previously mentioned up-regulation of miR393 under stress conditions, and consequent regulation of auxin signalling pathways, has been related to a reduction of plant growth observed in these situations (Sunkar \& Zhu, 2004).

Abnormal root growth and development has also been observed in several plant species subjected to osmotic stress (Bartels \& Sunkar, 2005). Recently, it was found that lateral root growth in arabidopsis depends on the tight feedback regulation between miR390, involved in the production of TAS3-derived ta-siRNAs, and an auxin responsive factor (ARF4), known to be targeted by these siRNAs (Allen et al., 2005; Marin et al., 2010). These results show that siRNAs can be involved in hormone signalling pathways during plant development as well, suggesting they could also regulate hormone-mediated responses to abiotic stress.

As mentioned earlier, miR393 was found to be involved in responses to bacterial infection in arabidopsis by regulating a group of auxin receptors (Navarro et al., 2006). Recently, other miRNAs, known to target hormone-related transcripts, were shown to be differentially expressed upon infection with different bacterial strains (Zhang et al., 2011a). These observations show that the relation between sRNAs and phytohormones can go beyond plant development and abiotic stress tolerance. 


\section{Regulation of small RNA pathways by abiotic stress}

RNA-mediated regulation of gene expression as response to abiotic stress conditions depends, not only on the expression of sRNAs and their targets, but it also seems to rely on the regulation of the proteins involved in their biosynthesis. In 2003, Szittya and co-workers have shown that virus and transgene-induced RNA silencing was dependent on temperature. The authors found that the accumulation of siRNAs, but not of miRNAs, was lower under cold stress and speculated that the activity of some DCL enzymes could be affected in these conditions (Szittya et al., 2003). Recently, in our laboratory we have shown that several $A G O$ and $D C L$ genes are differentially expressed in barrel medic adult plants subjected to water deficit (Capitão et al., 2011).

One striking feature of miRNA-mediated gene silencing in plants is that it is subjected to feedback self-regulation. Not only is DCL1, which is related to the biogenesis of most plant miRNAs, targeted by miR162 (Xie et al., 2003), but AGO1 is also known to stabilize miR168 and, simultaneously, be targeted by this miRNA (Rhoades et al., 2002; Vaucheret et al., 2004; Vaucheret et al., 2006). Strikingly, both miR162 and miR168 have been reported to be differentially expressed in abiotic stress conditions, like hypoxia (Zhang et al., 2008b), UV-B radiation (Jia et al., 2009a), water deficit (Zhou et al., 2010) and salt stress (Ding et al., 2009). This observation supports the idea that the expression of sRNAs, and therefore of target genes, can be regulated indirectly through the regulation of key enzymes of the biosynthesis pathway.

Interestingly, Moldovan and co-workers (2010), have reported a reduction in 24-nt long sRNAs and an increase in 21-nt long species in arabidopsis plants subjected to hypoxia, when compared to controlled conditions. This observation suggests that other enzymes, besides DCL1 and AGO1 can be regulated by environmental conditions. In fact, hen1, hyl1, hsty and se mutants are characterized by hypersensitivity to ABA, leading to a lower tolerance to osmotic stress (Lu \& Fedoroff, 2000; Zhang et al., 2008a). Also, the expression of RDR6, known to be involved in the biosynthesis of ta-siRNAs and nat-siRNAs, was recently shown to be induced by ABA (Yang et al., 2008).

Taken together, these results support the notion that altering sRNA biosynthesis pathways can affect the response to environmental conditions in plants. Whether the regulation of these proteins can also be mediated by other sRNAs, like it was found for DCL1 and AGO1, is yet to be investigated.

\section{Concluding remarks}

Despite the large amount of work published over the last years on sRNA-mediated regulation of gene expression under abiotic stress conditions, a lot of information is still missing on the functionality of most sRNAs. So far, this type of studies has been undertaken for just a few conserved miRNAs, several of them related to nutrient status in plants (reviewed by Sunkar et al., 2007).

In fact, the diversity of sRNAs, the observed redundancy in some biosynthesis pathways and their feedback regulation, unveil a higher complexity than previously thought when RNA silencing mechanisms were first identified in plants. Also, as reviewed in this manuscript, the expression of sRNAs seems to depend on a wide variety of factors, from plant species, to developmental stage, to growth conditions, among others, making it hard to fully understand their role under abiotic stress conditions.

Additionally, some recently identified non-conserved miRNAs seem to have no specific targets, or their experimental validation has proven difficult. In fact, computational tools for 
target prediction have been reported to yield a high percentage of false positives for these miRNAs (Moxon et al., 2008), which, at some extent, can account for that limitation. Nevertheless, a few of them were already shown to be differentially expressed in abiotic stress conditions, and are probably involved in more specific and less studied response mechanisms. In 2008, Addo-Quaye and co-workers have reported the sequencing of arabidopsis degradome, which is a technique that allows the high-throughput sequencing of mRNAs without the 5'-end cap, including degraded transcripts and targets of sRNA-mediated cleavage. Using this technique that does not rely on in silico predictions, the authors were able to confirm several previously identified targets, identify new targets for some miRNAs and tasiRNAs, and also to identify new TAS transcripts (Addo-Quaye et al., 2008). The sequencing of the degradome is now being adopted for other plant species (Addo-Quaye et al., 2009; Pantaleo et al., 2010) and is expected to retrieve interesting new information on the function and regulation of sRNAs in plants subjected to different conditions.

Phytohormones and stress-inducible TFs seem to play an important role in regulating the expression of miRNAs under abiotic stress conditions, in a similar way to what happens with protein-coding genes. Supporting this idea is the common observation that most miRNAs, besides targeting several TFs, also have stress-related cis-acting elements in their promoter regions. These data unveil a complex interaction between transcriptional and posttranscriptional regulators of gene expression that seems to be crucial to fine-tune responses to different environmental stimuli.

Additionally, when it comes to abiotic stress tolerance, most studies on sRNA-mediated regulation of gene expression have been performed inside laboratories, in highly controlled systems. However, in the wild, plants are hardly found in these conditions, and are usually subjected to different types of stresses at the same time. Interestingly, according to several studies, the responses to a situation of multiple simultaneous stresses can actually be different from the responses observed when two or three types of stress are induced separately (reviewed by Mittler, 2006). Therefore, some of the results already verified might even not be observed in the field, and care must be taken when analysing the function of sRNAs in these processes.

Over the last years, it has become clear that sRNAs play an important role in abiotic stress responses in plants. Moreover, they have also been related to pathogen infection and symbiosis (Navarro et al., 2006; Branscheid et al., 2010), revealing their importance in biotic stress conditions as well. Nevertheless, although a lot has been said on the biosynthesis and function of sRNAs, at the moment it seems to be just the tip of the iceberg and exciting new developments are expected in the near future.

\section{Acknowledgments}

The authors would like to thank José Ricardo Salvado for designing Figure 1. Inês Trindade was funded by a PhD fellowship from Fundação para a Ciência e Tecnologia (SFRH/BD/40738/2007).

\section{References}

Abdel-Ghany, S.E. \& Pilon, M. (2008). MicroRNA-mediated systemic down-regulation of copper protein expression in response to low copper availability in Arabidopsis. Journal of Biological Chemistry 283: 15932-15945. 
Addo-Quaye, C., Eshoo, T.W., Bartel, D.P. \& Axtell, M.J. (2008). Endogenous siRNA and miRNA targets identified by sequencing of the Arabidopsis degradome. Current Biology 18: 758-762.

Addo-Quaye, C., Snyder, J.A., Park, Y.B., Li, Y.F., Sunkar, R. \& Axtell, M.J. (2009). Sliced microRNA targets and precise loop-first processing of MIR319 hairpins revealed by analysis of the Physcomitrella patens degradome. RNA 15: 2112-2121.

Adenot, X., Elmayan, T., Lauressergues, D., Boutet, S., Bouche, N., Gasciolli, V. \& Vaucheret, H. (2006). DRB4-dependent TAS3 trans-acting siRNAs control leaf morphology through AGO7. Current Biology 16: 927-932.

Allen, E. \& Howell, M.D. (2010). miRNAs in the biogenesis of trans-acting siRNAs in higher plants. Seminars in Cell \& Developmental Biology 21: 798-804.

Allen, E., Xie, Z., Gustafson, A.M. \& Carrington, J.C. (2005). microRNA-directed phasing during trans-acting siRNA biogenesis in plants. Cell 121: 207-221.

Amor, B.B., Wirth, S., Merchan, F., Laporte, P., d'Aubenton-Carafa, Y., Hirsch, J., Maizel, A., Mallory, A., Lucas, A., Deragon, J.M., Vaucheret, H., Thermes, C. \& Crespi, M. (2009). Novel long non-protein coding RNAs involved in Arabidopsis differentiation and stress responses. Genome Research 19: 57-69.

Arenas-Huertero, C., Perez, B., Rabanal, F., Blanco-Melo, D., De la Rosa, C., EstradaNavarrete, G., Sanchez, F., Covarrubias, A.A. \& Reyes, J.L. (2009). Conserved and novel miRNAs in the legume Phaseolus vulgaris in response to stress. Plant Molecular Biology 70: 385-401.

Bartel, D.P. (2004). MicroRNAs: genomics, biogenesis, mechanism, and function. Cell 116: 281-297.

Bartels, D. \& Sunkar, R. (2005). Drought and Salt Tolerance in Plants. Critical Reviews in Plant Sciences 24: 23-58.

Baumberger, N. \& Baulcombe, D.C. (2005). Arabidopsis ARGONAUTE1 is an RNA Slicer that selectively recruits microRNAs and short interfering RNAs. Proceedings of the National Academy of Sciences of the United States of America 102: 11928-11933.

Bohnert, H.J. \& Sheveleva, E. (1998). Plant stress adaptations--making metabolism move. Current Opinion in plant Biology 1: 267-274.

Bonnet, E., Wuyts, J., Rouze, P. \& Van de Peer, Y. (2004). Detection of 91 potential conserved plant microRNAs in Arabidopsis thaliana and Oryza sativa identifies important target genes. Proceedings of the National Academy of Sciences of the United States of America 101: 11511-11516.

Borsani, O., Zhu, J., Verslues, P.E., Sunkar, R. \& Zhu, J.K. (2005). Endogenous siRNAs derived from a pair of natural cis-antisense transcripts regulate salt tolerance in Arabidopsis. Cell 123: 1279-1291.

Bouche, N., Lauressergues, D., Gasciolli, V. \& Vaucheret, H. (2006). An antagonistic function for Arabidopsis DCL2 in development and a new function for DCL4 in generating viral siRNAs. EMBO Journal 25: 3347-3356.

Boyko, A., Blevins, T., Yao, Y., Golubov, A., Bilichak, A., Ilnytskyy, Y., Hollunder, J., Meins, F., Jr. \& Kovalchuk, I. (2010). Transgenerational adaptation of Arabidopsis to stress requires DNA methylation and the function of Dicer-like proteins. PLoS One 5: e9514.

Branscheid, A., Sieh, D., Pant, B.D., May, P., Devers, E.A., Elkrog, A., Schauser, L., Scheible, W.R. \& Krajinski, F. (2010). Expression pattern suggests a role of MiR399 in the 
regulation of the cellular response to local $\mathrm{Pi}$ increase during arbuscular mycorrhizal symbiosis. Molecular Plant-Microbe Interactions 23: 915-926.

Capitão, C., Paiva, J.A.P., Santos, D.M. \& Fevereiro, P. (2011). Small RNA pathways are modulated by water deficit in Medicago truncatula. BMC Plant Biology. 11:79

Carrington, J.C. \& Ambros, V. (2003). Role of microRNAs in plant and animal development. Science 301: 336-338.

Chen, H.M., Chen, L.T., Patel, K., Li, Y.H., Baulcombe, D.C. \& Wu, S.H. (2010). 22Nucleotide RNAs trigger secondary siRNA biogenesis in plants. Proceedings of the National Academy of Sciences of the United States of America 107: 15269-15274.

Chen, X. (2004). A microRNA as a translational repressor of APETALA2 in Arabidopsis flower development. Science 303: 2022-2025.

Chinnusamy, V., Gong, Z. \& Zhu, J.K. (2008). Abscisic acid-mediated epigenetic processes in plant development and stress responses. Journal of Integrative Plant Biology 50: 11871195.

Chinnusamy, V., Zhu, J. \& Zhu, J.K. (2007). Cold stress regulation of gene expression in plants. Trends in Plant Science 12: 444-451.

Chinnusamy, V. \& Zhu, J.K. (2009). Epigenetic regulation of stress responses in plants. Current Opinion in plant Biology 12: 133-139.

Covarrubias, A.A. \& Reyes, J.L. (2010). Post-transcriptional gene regulation of salinity and drought responses by plant microRNAs. Plant, Cell E Environment 33: 481-489.

Cuperus, J.T., Carbonell, A., Fahlgren, N., Garcia-Ruiz, H., Burke, R.T., Takeda, A., Sullivan, C.M., Gilbert, S.D., Montgomery, T.A. \& Carrington, J.C. (2010). Unique functionality of 22-nt miRNAs in triggering RDR6-dependent siRNA biogenesis from target transcripts in Arabidopsis. Nature Structural \& Molecular Biology 17: 997-1003.

Dalmay, T., Hamilton, A., Rudd, S., Angell, S. \& Baulcombe, D.C. (2000). An RNAdependent RNA polymerase gene in Arabidopsis is required for posttranscriptional gene silencing mediated by a transgene but not by a virus. Cell 101: 543-553.

Ding, D., Zhang, L., Wang, H., Liu, Z., Zhang, Z. \& Zheng, Y. (2009). Differential expression of miRNAs in response to salt stress in maize roots. Annals of Botany 103: 29-38.

Dugas, D.V. \& Bartel, B. (2008). Sucrose induction of Arabidopsis miR398 represses two $\mathrm{Cu} / \mathrm{Zn}$ superoxide dismutases. Plant Molecular Biology 67: 403-417.

Foresight (2011). The Future of Food and Farming. Final Project Report. London: The Government Office for Science.

Frazier, T.P., Sun, G., Burklew, C.E. \& Zhang, B. (2011). Salt and Drought Stresses Induce the Aberrant Expression of microRNA Genes in Tobacco. Molecular Biotechnology.

Gasciolli, V., Mallory, A.C., Bartel, D.P. \& Vaucheret, H. (2005). Partially redundant functions of Arabidopsis DICER-like enzymes and a role for DCL4 in producing trans-acting siRNAs. Current Biology 15: 1494-1500.

Griffiths-Jones, S. (2004). The microRNA Registry. Nucleic Acids Res 32: D109-111.

Guo, H.S., Xie, Q., Fei, J.F. \& Chua, N.H. (2005). MicroRNA directs mRNA cleavage of the transcription factor NAC1 to downregulate auxin signals for arabidopsis lateral root development. Plant Cell 17: 1376-1386.

Hamilton, A., Voinnet, O., Chappell, L. \& Baulcombe, D. (2002). Two classes of short interfering RNA in RNA silencing. EMBO Journal 21: 4671-4679. 
Hamilton, A.J. \& Baulcombe, D.C. (1999). A species of small antisense RNA in posttranscriptional gene silencing in plants. Science 286: 950-952.

Han, M.H., Goud, S., Song, L. \& Fedoroff, N. (2004). The Arabidopsis double-stranded RNAbinding protein HYL1 plays a role in microRNA-mediated gene regulation. Proceedings of the National Academy of Sciences of the United States of America 101: 1093-1098.

Harvey, J.J., Lewsey, M.G., Patel, K., Westwood, J., Heimstadt, S., Carr, J.P. \& Baulcombe, D.C. (2011). An Antiviral Defense Role of AGO2 in Plants. PLoS One 6: e14639.

Henderson, I.R., Zhang, X., Lu, C., Johnson, L., Meyers, B.C., Green, P.J. \& Jacobsen, S.E. (2006). Dissecting Arabidopsis thaliana DICER function in small RNA processing, gene silencing and DNA methylation patterning. Nature Genetics 38: 721-725.

Herr, A.J., Jensen, M.B., Dalmay, T. \& Baulcombe, D.C. (2005). RNA polymerase IV directs silencing of endogenous DNA. Science 308: 118-120.

Hirayama, T. \& Shinozaki, K. (2010). Research on plant abiotic stress responses in the postgenome era: past, present and future. Plant Journal 61: 1041-1052.

Iglesias, M.J., Terrile, M.C., Bartoli, C.G., D'Ippolito, S. \& Casalongue, C.A. (2010). Auxin signaling participates in the adaptative response against oxidative stress and salinity by interacting with redox metabolism in Arabidopsis. Plant Molecular Biology 74: 215-222.

Iida, K., Seki, M., Sakurai, T., Satou, M., Akiyama, K., Toyoda, T., Konagaya, A. \& Shinozaki, K. (2004). Genome-wide analysis of alternative pre-mRNA splicing in Arabidopsis thaliana based on full-length cDNA sequences. Nucleic Acids Research 32: 5096-5103.

Iki, T., Yoshikawa, M., Nishikiori, M., Jaudal, M.C., Matsumoto-Yokoyama, E., Mitsuhara, I., Meshi, T. \& Ishikawa, M. (2010). In vitro assembly of plant RNA-induced silencing complexes facilitated by molecular chaperone HSP90. Molecular Cell 39: 282-291.

Jagadeeswaran, G., Saini, A. \& Sunkar, R. (2009). Biotic and abiotic stress down-regulate miR398 expression in Arabidopsis. Planta 229: 1009-1014.

Jia, X., Ren, L., Chen, Q.J., Li, R. \& Tang, G. (2009a). UV-B-responsive microRNAs in Populus tremula. Journal of Plant Physiology 166: 2046-2057.

Jia, X., Wang, W.X., Ren, L., Chen, Q.J., Mendu, V., Willcut, B., Dinkins, R., Tang, X. \& Tang, G. (2009b). Differential and dynamic regulation of miR398 in response to ABA and salt stress in Populus tremula and Arabidopsis thaliana. Plant Molecular Biology 71: 51-59.

Jones-Rhoades, M.W. \& Bartel, D.P. (2004). Computational identification of plant microRNAs and their targets, including a stress-induced miRNA. Molecular Cell 14: 787-799.

Kantar, M., Lucas, S.J. \& Budak, H. (2011). miRNA expression patterns of Triticum dicoccoides in response to shock drought stress. Planta 233: 471-484.

Kantar, M., Unver, T. \& Budak, H. (2010). Regulation of barley miRNAs upon dehydration stress correlated with target gene expression. Functional \& Integrative Genomics 10: 493-507.

Kliebenstein, D.J., Monde, R.A. \& Last, R.L. (1998). Superoxide dismutase in Arabidopsis: an eclectic enzyme family with disparate regulation and protein localization. Plant Physiology 118: 637-650.

Li, J., Yang, Z., Yu, B., Liu, J. \& Chen, X. (2005). Methylation protects miRNAs and siRNAs from a 3'-end uridylation activity in Arabidopsis. Current Biology 15: 1501-1507. 
Li, T., Li, H., Zhang, Y.X. \& Liu, J.Y. (2010). Identification and analysis of seven H2O2responsive miRNAs and 32 new miRNAs in the seedlings of rice (Oryza sativa L. ssp. indica). Nucleic Acids Research.

Licausi, F. (2010). Regulation of the molecular response to oxygen limitations in plants. New Phytologist DOI: 10.1111/j.1469-8137.2010.03562.x.

Liu, B., Li, P., Li, X., Liu, C., Cao, S., Chu, C. \& Cao, X. (2005). Loss of function of OsDCL1 affects microRNA accumulation and causes developmental defects in rice. Plant Physiology 139: 296-305.

Liu, H.H., Tian, X., Li, Y.J., Wu, C.A. \& Zheng, C.C. (2008). Microarray-based analysis of stress-regulated microRNAs in Arabidopsis thaliana. RNA 14: 836-843.

Liu, Q. \& Chen, Y.Q. (2009). Insights into the mechanism of plant development: interactions of miRNAs pathway with phytohormone response. Biochemical and Biophysical Research Communications 384: 1-5.

Liu, Q., Zhang, Y.C., Wang, C.Y., Luo, Y.C., Huang, Q.J., Chen, S.Y., Zhou, H., Qu, L.H. \& Chen, Y.Q. (2009). Expression analysis of phytohormone-regulated microRNAs in rice, implying their regulation roles in plant hormone signaling. FEBS Letters 583: 723-728.

Llave, C., Kasschau, K.D., Rector, M.A. \& Carrington, J.C. (2002a). Endogenous and silencing-associated small RNAs in plants. Plant Cell 14: 1605-1619.

Llave, C., Xie, Z., Kasschau, K.D. \& Carrington, J.C. (2002b). Cleavage of Scarecrow-like mRNA targets directed by a class of Arabidopsis miRNA. Science 297: 2053-2056.

Lobbes, D., Rallapalli, G., Schmidt, D.D., Martin, C. \& Clarke, J. (2006). SERRATE: a new player on the plant microRNA scene. EMBO Reports 7: 1052-1058.

Lu, C. \& Fedoroff, N. (2000). A mutation in the Arabidopsis HYL1 gene encoding a dsRNA binding protein affects responses to abscisic acid, auxin, and cytokinin. Plant Cell 12: 2351-2366.

Lu, S., Sun, Y.H. \& Chiang, V.L. (2008). Stress-responsive microRNAs in Populus. Plant Journal 55: 131-151.

Lurin, C., Andres, C., Aubourg, S., Bellaoui, M., Bitton, F., Bruyere, C., Caboche, M., Debast, C., Gualberto, J., Hoffmann, B., Lecharny, A., Le Ret, M., Martin-Magniette, M.L., Mireau, H., Peeters, N., Renou, J.P., Szurek, B., Taconnat, L. \& Small, I. (2004). Genome-wide analysis of Arabidopsis pentatricopeptide repeat proteins reveals their essential role in organelle biogenesis. Plant Cell 16: 2089-2103.

Lv, D.K., Bai, X., Li, Y., Ding, X.D., Ge, Y., Cai, H., Ji, W., Wu, N. \& Zhu, Y.M. (2010). Profiling of cold-stress-responsive miRNAs in rice by microarrays. Gene 459: 39-47.

Mallory, A. \& Vaucheret, H. (2010). Form, function, and regulation of ARGONAUTE proteins. Plant Cell 22: 3879-3889.

Marin, E., Jouannet, V., Herz, A., Lokerse, A.S., Weijers, D., Vaucheret, H., Nussaume, L., Crespi, M.D. \& Maizel, A. (2010). miR390, Arabidopsis TAS3 tasiRNAs, and their AUXIN RESPONSE FACTOR targets define an autoregulatory network quantitatively regulating lateral root growth. Plant Cell 22: 1104-1117.

Meyers, B.C., Axtell, M.J., Bartel, B., Bartel, D.P., Baulcombe, D., Bowman, J.L., Cao, X., Carrington, J.C., Chen, X., Green, P.J., Griffiths-Jones, S., Jacobsen, S.E., Mallory, A.C., Martienssen, R.A., Poethig, R.S., Qi, Y., Vaucheret, H., Voinnet, O., Watanabe, Y., Weigel, D. \& Zhu, J.K. (2008). Criteria for annotation of plant MicroRNAs. Plant Cell 20: 3186-3190. 
Mi, S., Cai, T., Hu, Y., Chen, Y., Hodges, E., Ni, F., Wu, L., Li, S., Zhou, H., Long, C., Chen, S., Hannon, G.J. \& Qi, Y. (2008). Sorting of small RNAs into Arabidopsis argonaute complexes is directed by the 5 ' terminal nucleotide. Cell 133: 116-127.

Mittler, R. (2006). Abiotic stress, the field environment and stress combination. Trends in Plant Science 11: 15-19.

Moldovan, D., Spriggs, A., Yang, J., Pogson, B.J., Dennis, E.S. \& Wilson, I.W. (2010). Hypoxia-responsive microRNAs and trans-acting small interfering RNAs in Arabidopsis. Journal of Experimental Botany 61: 165-177.

Montgomery, T.A., Howell, M.D., Cuperus, J.T., Li, D., Hansen, J.E., Alexander, A.L., Chapman, E.J., Fahlgren, N., Allen, E. \& Carrington, J.C. (2008a). Specificity of ARGONAUTE7-miR390 interaction and dual functionality in TAS3 trans-acting siRNA formation. Cell 133: 128-141.

Montgomery, T.A., Yoo, S.J., Fahlgren, N., Gilbert, S.D., Howell, M.D., Sullivan, C.M., Alexander, A., Nguyen, G., Allen, E., Ahn, J.H. \& Carrington, J.C. (2008b). AGO1miR173 complex initiates phased siRNA formation in plants. Proceedings of the National Academy of Sciences of the United States of America 105: 20055-20062.

Moxon, S., Jing, R., Szittya, G., Schwach, F., Rusholme Pilcher, R.L., Moulton, V. \& Dalmay, T. (2008). Deep sequencing of tomato short RNAs identifies microRNAs targeting genes involved in fruit ripening. Genome Research 18: 1602-1609.

Nakashima, K., Ito, Y. \& Yamaguchi-Shinozaki, K. (2009). Transcriptional regulatory networks in response to abiotic stresses in Arabidopsis and grasses. Plant Physiology 149: 88-95.

Navarro, L., Dunoyer, P., Jay, F., Arnold, B., Dharmasiri, N., Estelle, M., Voinnet, O. \& Jones, J.D. (2006). A plant miRNA contributes to antibacterial resistance by repressing auxin signaling. Science 312: 436-439.

Nelson, D.E., Repetti, P.P., Adams, T.R., Creelman, R.A., Wu, J., Warner, D.C., Anstrom, D.C., Bensen, R.J., Castiglioni, P.P., Donnarummo, M.G., Hinchey, B.S., Kumimoto, R.W., Maszle, D.R., Canales, R.D., Krolikowski, K.A., Dotson, S.B., Gutterson, N., Ratcliffe, O.J. \& Heard, J.E. (2007). Plant nuclear factor Y (NF-Y) B subunits confer drought tolerance and lead to improved corn yields on water-limited acres. Proceedings of the National Academy of Sciences of the United States of America 104: 16450-16455.

Pantaleo, V., Szittya, G., Moxon, S., Miozzi, L., Moulton, V., Dalmay, T. \& Burgyan, J. (2010). Identification of grapevine microRNAs and their targets using high-throughput sequencing and degradome analysis. Plant Journal 62: 960-976.

Park, M.Y., Wu, G., Gonzalez-Sulser, A., Vaucheret, H. \& Poethig, R.S. (2005). Nuclear processing and export of microRNAs in Arabidopsis. Proceedings of the National Academy of Sciences of the United States of America 102: 3691-3696.

Park, W., Li, J., Song, R., Messing, J. \& Chen, X. (2002). CARPEL FACTORY, a Dicer homolog, and HEN1, a novel protein, act in microRNA metabolism in Arabidopsis thaliana. Current Biology 12: 1484-1495.

Rajagopalan, R., Vaucheret, H., Trejo, J. \& Bartel, D.P. (2006). A diverse and evolutionarily fluid set of microRNAs in Arabidopsis thaliana. Genes \& Development 20: 3407-3425.

Ramachandran, V. \& Chen, X. (2008). Small RNA metabolism in Arabidopsis. Trends in Plant Science 13: 368-374. 
Reinhart, B.J., Weinstein, E.G., Rhoades, M.W., Bartel, B. \& Bartel, D.P. (2002). MicroRNAs in plants. Genes \& Development 16: 1616-1626.

Reyes, J.L. \& Chua, N.H. (2007). ABA induction of miR159 controls transcript levels of two MYB factors during Arabidopsis seed germination. Plant Journal 49: 592-606.

Rhoades, M.W., Reinhart, B.J., Lim, L.P., Burge, C.B., Bartel, B. \& Bartel, D.P. (2002). Prediction of plant microRNA targets. Cell 110: 513-520.

Ruegger, M., Dewey, E., Gray, W.M., Hobbie, L., Turner, J. \& Estelle, M. (1998). The TIR1 protein of Arabidopsis functions in auxin response and is related to human SKP2 and yeast grr1p. Genes \& Development 12: 198-207.

Schreiber, A.W., Shi, B.J., Huang, C.Y., Langridge, P. \& Baumann, U. (2011). Discovery of Barley miRNAs through Deep Sequencing of Short Reads. BMC Genomics 12: 129.

Shinozaki, K. \& Yamaguchi-Shinozaki, K. (2007). Gene networks involved in drought stress response and tolerance. Journal of Experimental Botany 58: 221-227.

Sire, C., Moreno, A.B., Garcia-Chapa, M., Lopez-Moya, J.J. \& San Segundo, B. (2009). Diurnal oscillation in the accumulation of Arabidopsis microRNAs, miR167, miR168, miR171 and miR398. FEBS Letters 583: 1039-1044.

Song, Q.X., Liu, Y.F., Hu, X.Y., Zhang, W.K., Ma, B., Chen, S.Y. \& Zhang, J.S. (2011). Identification of miRNAs and their target genes in developing soybean seeds by deep sequencing. BMC Plant Biology 11: 5.

Sorin, C., Bussell, J.D., Camus, I., Ljung, K., Kowalczyk, M., Geiss, G., McKhann, H., Garcion, C., Vaucheret, H., Sandberg, G. \& Bellini, C. (2005). Auxin and light control of adventitious rooting in Arabidopsis require ARGONAUTE1. Plant Cell 17: 1343-1359.

Sunkar, R., Chinnusamy, V., Zhu, J. \& Zhu, J.K. (2007). Small RNAs as big players in plant abiotic stress responses and nutrient deprivation. Trends in Plant Science 12: 301-309.

Sunkar, R., Kapoor, A. \& Zhu, J.K. (2006). Posttranscriptional induction of two Cu/Zn superoxide dismutase genes in Arabidopsis is mediated by downregulation of miR398 and important for oxidative stress tolerance. Plant Cell 18: 2051-2065.

Sunkar, R. \& Zhu, J.K. (2004). Novel and stress-regulated microRNAs and other small RNAs from Arabidopsis. Plant Cell 16: 2001-2019.

Szittya, G., Moxon, S., Santos, D.M., Jing, R., Fevereiro, M.P., Moulton, V. \& Dalmay, T. (2008). High-throughput sequencing of Medicago truncatula short RNAs identifies eight new miRNA families. BMC Genomics 9: 593.

Szittya, G., Silhavy, D., Molnar, A., Havelda, Z., Lovas, A., Lakatos, L., Banfalvi, Z. \& Burgyan, J. (2003). Low temperature inhibits RNA silencing-mediated defence by the control of siRNA generation. EMBO Journal 22: 633-640.

Todesco, M., Rubio-Somoza, I., Paz-Ares, J. \& Weigel, D. (2010). A collection of target mimics for comprehensive analysis of microRNA function in Arabidopsis thaliana. PLoS Genetics 6: e1001031.

Trindade, I., Capitao, C., Dalmay, T., Fevereiro, M.P. \& Santos, D.M. (2010). miR398 and miR408 are up-regulated in response to water deficit in Medicago truncatula. Planta 231: 705-716.

Vanneste, S. \& Friml, J. (2009). Auxin: a trigger for change in plant development. Cell 136: 1005-1016. 
Vaucheret, H., Mallory, A.C. \& Bartel, D.P. (2006). AGO1 homeostasis entails coexpression of MIR168 and AGO1 and preferential stabilization of miR168 by AGO1. Molecular Cell 22: 129-136.

Vaucheret, H., Vazquez, F., Crete, P. \& Bartel, D.P. (2004). The action of ARGONAUTE1 in the miRNA pathway and its regulation by the miRNA pathway are crucial for plant development. Genes \& Development 18: 1187-1197.

Vazquez, F., Vaucheret, H., Rajagopalan, R., Lepers, C., Gasciolli, V., Mallory, A.C., Hilbert, J.L., Bartel, D.P. \& Crete, P. (2004). Endogenous trans-acting siRNAs regulate the accumulation of Arabidopsis mRNAs. Molecular Cell 16: 69-79.

Wang, J.F., Zhou, H., Chen, Y.Q., Luo, Q.J. \& Qu, L.H. (2004). Identification of 20 microRNAs from Oryza sativa. Nucleic Acids Research 32: 1688-1695.

Wu, M.F., Tian, Q. \& Reed, J.W. (2006). Arabidopsis microRNA167 controls patterns of ARF6 and ARF8 expression, and regulates both female and male reproduction. Development 133: 4211-4218.

Xie, Z., Allen, E., Fahlgren, N., Calamar, A., Givan, S.A. \& Carrington, J.C. (2005). Expression of Arabidopsis MIRNA genes. Plant Physiology 138: 2145-2154.

Xie, Z., Kasschau, K.D. \& Carrington, J.C. (2003). Negative feedback regulation of DicerLike1 in Arabidopsis by microRNA-guided mRNA degradation. Current Biology 13: 784-789.

Yang, J.H., Seo, H.H., Han, S.J., Yoon, E.K., Yang, M.S. \& Lee, W.S. (2008). Phytohormone abscisic acid control RNA-dependent RNA polymerase 6 gene expression and posttranscriptional gene silencing in rice cells. Nucleic Acids Research 36: 1220-1226.

Yoshikawa, M., Peragine, A., Park, M.Y. \& Poethig, R.S. (2005). A pathway for the biogenesis of trans-acting siRNAs in Arabidopsis. Genes $\mathcal{E}$ Development 19: 2164-2175.

Yu, B., Yang, Z., Li, J., Minakhina, S., Yang, M., Padgett, R.W., Steward, R. \& Chen, X. (2005). Methylation as a crucial step in plant microRNA biogenesis. Science 307: 932-935.

Zhang, J.F., Yuan, L.J., Shao, Y., Du, W., Yan, D.W. \& Lu, Y.T. (2008a). The disturbance of small RNA pathways enhanced abscisic acid response and multiple stress responses in Arabidopsis. Plant, Cell E Environment 31: 562-574.

Zhang, W., Gao, S., Zhou, X., Chellappan, P., Chen, Z., Zhang, X., Fromuth, N., Coutino, G., Coffey, M. \& Jin, H. (2011a). Bacteria-responsive microRNAs regulate plant innate immunity by modulating plant hormone networks. Plant Molecular Biology 75: 93105.

Zhang, X., Zou, Z., Gong, P., Zhang, J., Ziaf, K., Li, H., Xiao, F. \& Ye, Z. (2011b). Overexpression of microRNA169 confers enhanced drought tolerance to tomato. Biotechnology Letters 33: 403-409.

Zhang, Z., Wei, L., Zou, X., Tao, Y., Liu, Z. \& Zheng, Y. (2008b). Submergence-responsive MicroRNAs are potentially involved in the regulation of morphological and metabolic adaptations in maize root cells. Annals of Botany 102: 509-519.

Zhao, B., Ge, L., Liang, R., Li, W., Ruan, K., Lin, H. \& Jin, Y. (2009). Members of miR-169 family are induced by high salinity and transiently inhibit the NF-YA transcription factor. BMC Molecular Biology 10: 29.

Zhao, B., Liang, R., Ge, L., Li, W., Xiao, H., Lin, H., Ruan, K. \& Jin, Y. (2007). Identification of drought-induced microRNAs in rice. Biochemical and Biophysical Research Communications 354: 585-590. 
Zhou, L., Liu, Y., Liu, Z., Kong, D., Duan, M. \& Luo, L. (2010). Genome-wide identification and analysis of drought-responsive microRNAs in Oryza sativa. Journal of Experimental Botany 61: 4157-4168.

Zhou, X., Wang, G., Sutoh, K., Zhu, J.K. \& Zhang, W. (2008). Identification of cold-inducible microRNAs in plants by transcriptome analysis. Biochimica et Biophysica Acta 1779: 780-788.

Zhou, X., Wang, G. \& Zhang, W. (2007). UV-B responsive microRNA genes in Arabidopsis thaliana. Molecular Systems Biology 3: 103.

Zhu, J.K. (2002). Salt and drought stress signal transduction in plants. Annual Review of Plant Biology 53: 247-273.

Zilberman, D., Cao, X. \& Jacobsen, S.E. (2003). ARGONAUTE4 control of locus-specific siRNA accumulation and DNA and histone methylation. Science 299: 716-719. 


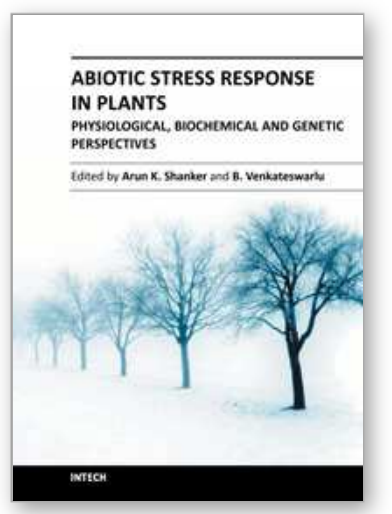

\author{
Abiotic Stress Response in Plants - Physiological, Biochemical \\ and Genetic Perspectives \\ Edited by Prof. Arun Shanker
}

ISBN 978-953-307-672-0

Hard cover, 346 pages

Publisher InTech

Published online 29, August, 2011

Published in print edition August, 2011

Plants, unlike animals, are sessile. This demands that adverse changes in their environment are quickly recognized, distinguished and responded to with suitable reactions. Drought, heat, cold and salinity are among the major abiotic stresses that adversely affect plant growth and productivity. In general, abiotic stress often causes a series of morphological, physiological, biochemical and molecular changes that unfavorably affect plant growth, development and productivity. Drought, salinity, extreme temperatures (cold and heat) and oxidative stress are often interrelated; these conditions singularly or in combination induce cellular damage. To cope with abiotic stresses, of paramount significance is to understand plant responses to abiotic stresses that disturb the homeostatic equilibrium at cellular and molecular level in order to identify a common mechanism for multiple stress tolerance. This multi authored edited compilation attempts to put forth an all-inclusive biochemical and molecular picture in a systems approach wherein mechanism and adaptation aspects of abiotic stress are dealt with. The chief objective of the book hence is to deliver state of the art information for comprehending the effects of abiotic stress in plants at the cellular level.

\title{
How to reference
}

In order to correctly reference this scholarly work, feel free to copy and paste the following:

Inês Trindade, Dulce Santos, Tamas Dalmay and Pedro Fevereiro (2011). Facing the Environment: Small RNAs and the Regulation of Gene Expression Under Abiotic Stress in Plants, Abiotic Stress Response in Plants - Physiological, Biochemical and Genetic Perspectives, Prof. Arun Shanker (Ed.), ISBN: 978-953-307-672-0, InTech, Available from: http://www.intechopen.com/books/abiotic-stress-response-in-plants-physiologicalbiochemical-and-genetic-perspectives/facing-the-environment-small-rnas-and-the-regulation-of-geneexpression-under-abiotic-stress-in-pla1

\section{INTECH}

open science | open minds

\author{
InTech Europe \\ University Campus STeP Ri \\ Slavka Krautzeka 83/A \\ 51000 Rijeka, Croatia \\ Phone: +385 (51) 770447 \\ Fax: +385 (51) 686166 \\ www.intechopen.com
}

\author{
InTech China \\ Unit 405, Office Block, Hotel Equatorial Shanghai \\ No.65, Yan An Road (West), Shanghai, 200040, China \\ 中国上海市延安西路65号上海国际贵都大饭店办公楼 405 单元 \\ Phone: +86-21-62489820 \\ Fax: +86-21-62489821
}


(C) 2011 The Author(s). Licensee IntechOpen. This chapter is distributed under the terms of the Creative Commons Attribution-NonCommercialShareAlike-3.0 License, which permits use, distribution and reproduction for non-commercial purposes, provided the original is properly cited and derivative works building on this content are distributed under the same license. 